\title{
ARTERIOGRAPHIC EVIDENCE FOR A CHOLINERGIC DILATOR MECHANISM IN UTERINE HYPERAEMIA OF PREGNANCY IN THE GUINEA-PIG
}

\author{
C. BELL* AND M. J. BROWN $\dagger$ \\ ARC Institute of Animal Physiology, Babraham, Cambridge
}

(Received 21st October 1970)

\begin{abstract}
Summary. Retrograde arteriography has been used to examine the effect of pregnancy on the diameters of the main uterine, internal iliac and inferior epigastric arteries in the guinea-pig. The diameters of the internal iliac and inferior epigastric arteries were not altered during gestation. By contrast, the diameter of the main uterine artery supplying a pregnant horn of the uterus increased in diameter to a mean value of $167 \%$ of its diameter in non-pregnancy. In cases of unilateral pregnancy, the uterine artery supplying the non-pregnant horn of the uterus was not increased in diameter. Administration of atropine $(0.1$ to $0.5 \mathrm{mg} / \mathrm{kg})$ to animals in late pregnancy caused constriction of the enlarged uterine arteries to a mean value of $137 \%$ of their pre-pregnant diameter, but the diameters of the internal iliac and inferior epigastric arteries were not changed. In non-pregnant animals, the diameter of the uterine arteries was not affected by atropine. The results support previous evidence for an effector rôle of cholinergic vasodilator nerves in the production of uterine hyperaemia during pregnancy in the guinea-pig.
\end{abstract}

\section{INTRODUCTION}

Although it is well established that a massive increase in blood flow to the uterus occurs during pregnancy (Barcroft \& Barron, 1946; Reynolds, 1949; Metcalfe, Romney, Ramsey, Reid \& Burwell, 1955; Orsini, 1957; Ramsey, 1959; Assali, Rauramo \& Peltonen, 1960; Greiss \& Anderson, 1970), the mechanisms underlying this increase are unknown.

Recently, it has been found that the main extrinsic uterine artery of the guinea-pig is innervated by cholinergic vasodilator nerve fibres (Bell, 1968, 1969a). The arterial muscle responds to acetylcholine and to cholinergic stimulation only during the latter half of pregnancy, a situation which led Bell (1968) to suggest that this vasodilator innervation might be implicated in the uterine hyperaemia of pregnancy in the guinea-pig. A more recent finding that similar nerves appear to supply the extrinsic uterine vessels in both dog and man (Bell, 1969b) has accentuated the possible importance of this system.

In the present paper, arteriography has been used to study the uterine

* Present address: Department of Zoology, University of Melbourne, Parkville, Victoria 3052, Australia.

$\dagger$ Present address: Food Research Institute, Colney Lane, Norwich. 
vasculature of the guinea-pig in vivo. Observations have been made of the effect of pregnancy on the diameters of uterine and other arteries, and the postulate that a cholinergic dilator mechanism is involved in uterine hyperaemia has been tested by administration of atropine.

\section{MATERIALS AND METHODS}

Virgin albino guinea-pigs of 500 to $600 \mathrm{~g}$ in weight were used. Some animals were mated and others were maintained as a non-pregnant stock. The progress of pregnancy was calculated from the day on which a vaginal plug was found (Day 1) and checked by comparison of the foetal length on the day of experimentation with the chart published by Draper (1920). The gestational age at which pregnant animals were used was 40 or more days.

The animals were anaesthetized with pentobarbitone sodium $(40 \mathrm{mg} / \mathrm{kg})$ i.p. and tied in a supine position on to a frame covered with $\frac{1}{18}$ in. polythene sheeting. This frame was of a height such that the standard X-ray film cassettes used fitted snugly below it. One femoral artery was exposed and the area around the origin of the genicular arteries was moistened with $1 \%$ sodium nitrite solution on a cotton-wool swab. This treatment was found necessary to prevent closure of the vessel during the subsequent catheterization. A catheter of pp. 30 polyethylene tubing filled with heparinized saline was passed in a retrograde manner up the femoral artery until it was judged to lie near the bifurcation of the aorta, when it was tied into place.

Several different radio-opaque media (Triosil 45 and 75, Glaxo; Diaginol 50 , May \& Baker) and procedures of injection and photography were tried. Triosil 75 was chosen as giving the best and most consistent results and was injected manually in a slug of $0.5 \mathrm{ml}$ over a 4-sec period, using a 2-ml syringe. As no automatic cassette changer was available, only one photograph could be taken during each injection period. It was established that maximal filling of the vessels with medium was obtained over the last second of injection, and the time of photographic exposure was standardized at $3.5 \mathrm{sec}$ after commencement of the injection.

The tube-film distance was maintained at $100 \mathrm{~cm}$ with a focal spot size of $1 \cdot 2$ $\mathrm{mm}$ and X-rays were generated with an Elema Pleromobil 300D generator using $120 \mathrm{~mA}$ and $50 \mathrm{kV}$. Exposure time was $0.06 \mathrm{sec}$. The most satisfactory resolution and contrast was obtained using Agfa-Gevaert Curix P film. However, this became unavailable during the course of the investigation and in the last few experiments, Kodak Royal Blue film was used.

Medium was injected at intervals of at least $1 \mathrm{~min}$. Generally, the interval between injections was about $5 \mathrm{~min}$, as the preceding photograph was developed before taking the next. Following at least two control photographs, atropine sulphate in $0.9 \% \mathrm{NaCl}$ was infused by way of the intra-arterial catheter over 2 to $5 \mathrm{~min}$ in a total dose of $0.1,0.5 \mathrm{or} 1.0 \mathrm{mg} / \mathrm{kg}$. The volume of this infusion was $2 \mathrm{ml}$. After a period of 10 to $15 \mathrm{~min}$, further photographs were taken. Development time was standardized throughout so as to minimize errors in vessel size due to variations in image contrast. The results obtained were similar with both types of film used. 
For the measurement of arterial diameters, positive prints with a magnification of $\times 5$ were made from the original X-ray plates. This was the highest magnification which could be obtained without excessive loss of resolution. The photographs from each experiment were examined to determine points on the main uterine, internal iliac and inferior epigastric arteries which could be used for measurement of diameters both before and after atropine administration. Although the exact points used varied between experiments, they fell in the following ranges: uterine artery, 1 to $5 \mathrm{~cm}$ from its junction with the internal iliac; internal iliac, 1 to $3 \mathrm{~cm}$ from its origin; inferior epigastric, 0.5 to $1 \mathrm{~cm}$ from its origin (see Pl. 1, Figs. $1 \mathrm{a}$ and b). Over these distances, there was no appreciable variation in diameter of the vessels. The points at which measurements were to be made were marked on each print, and vessel diameters were assessed to the nearest $0.5 \mathrm{~mm}$ by two observers who had no knowledge of the other observer's measurements or of the origin of any particular print. The statistical difference of means was determined using Student's $t$ test (Fisher, 1936).

\section{TABLE 1}

AVERAGE DIAMETERS $(\mathrm{mm} \times 5)$ OF MAIN UTERINE, INTERNAL ILIAC AND INFERIOR EPIGASTRIC ARTERIES IN VIRGIN ANIMALS BEFORE AND AFTER ATROPINE ADMINISTRATION

\begin{tabular}{|c|c|c|c|c|c|c|c|c|c|}
\hline \multirow{2}{*}{ Exp. } & \multicolumn{3}{|c|}{ Uterine } & \multicolumn{3}{|c|}{ Int. iliac } & \multicolumn{3}{|c|}{ Inf. epigastric } \\
\hline & Before & After & Diff. & Before & After & Diff. & Before & After & Diff. \\
\hline 1 & 2.00 & - & & 3.00 & - & & 3.50 & & \\
\hline 2 (a) & $\begin{array}{l}2 \cdot 25 \\
2 \cdot 50\end{array}$ & $\begin{array}{c}2 \cdot 50 \\
-\end{array}$ & $+0 \cdot 25$ & $\begin{array}{l}2 \cdot 70 \\
2 \cdot 50\end{array}$ & $\stackrel{2 \cdot 50}{-}$ & $-0 \cdot 20$ & $4 \cdot 70$ & - & \\
\hline $\begin{array}{l}3 \text { (a) } \\
\text { (b) }\end{array}$ & $\begin{array}{l}2 \cdot 50 \\
2 \cdot 50\end{array}$ & $\begin{array}{l}2 \cdot 50 \\
2 \cdot 50\end{array}$ & $\begin{array}{l}0 \\
0\end{array}$ & $\begin{array}{l}3 \cdot 00 \\
2 \cdot 50\end{array}$ & $\begin{array}{l}2.75 \\
2.50\end{array}$ & $\begin{array}{c}-0.25 \\
0\end{array}$ & $\begin{array}{c}4.00 \\
-\end{array}$ & $3 \cdot 80$ & -0.20 \\
\hline 4 (a) & $\begin{array}{l}2 \cdot 00 \\
2 \cdot 25\end{array}$ & $\begin{array}{l}2 \cdot 50 \\
2 \cdot 50\end{array}$ & $\begin{array}{l}+0.50 \\
+0.25\end{array}$ & $\begin{array}{l}2 \cdot 50 \\
2 \cdot 50\end{array}$ & $\begin{array}{l}2 \cdot 50 \\
2 \cdot 50\end{array}$ & $\begin{array}{l}0 \\
0\end{array}$ & $\begin{array}{l}4.00 \\
4.00\end{array}$ & $\begin{array}{l}4 \cdot 00 \\
4 \cdot 00\end{array}$ & $\begin{array}{l}0 \\
0\end{array}$ \\
\hline Mean & $\begin{array}{r}2.28 \\
\pm 0.09\end{array}$ & $\begin{array}{r}2.50 \\
\pm 0.00\end{array}$ & $+0 \cdot 22^{*}$ & $\begin{array}{r}2.67 \\
\pm 0.09\end{array}$ & $\begin{array}{r}2.55 \\
\pm 0.05\end{array}$ & $-0 \cdot 12^{* *}$ & $\begin{array}{r}4.06 \\
\pm 0.16\end{array}$ & $\begin{array}{l}3.93 \\
\pm 0.0\end{array}$ & $-0 \cdot 13^{* * *}$ \\
\hline
\end{tabular}

${ }^{*} P>0 \cdot 1 ; * * P>0.3 ; * * * P>0.5$.

The quantitative results reported were obtained on eight pregnant and four virgin animals. Several additional experiments were performed but had to be rejected due to lack of photographic resolution which made accurate measurements impossible.

\section{RESULTS}

The diameters of uterine, internal iliac and inferior epigastric arteries in four virgin animals are tabulated in Table 1 . Mean values were 2.28, 2.67 and 4.06 $\mathrm{mm}$, respectively, as measured from the enlarged plates, corresponding to approximate actual diameters of $0.46,0.53$ and $0.81 \mathrm{~mm}$. Atropine which was administered to three animals in final doses of 0.5 to $1.0 \mathrm{mg} / \mathrm{kg}$ had no significant effect on the diameters of any of these arteries (Table 1 ). 


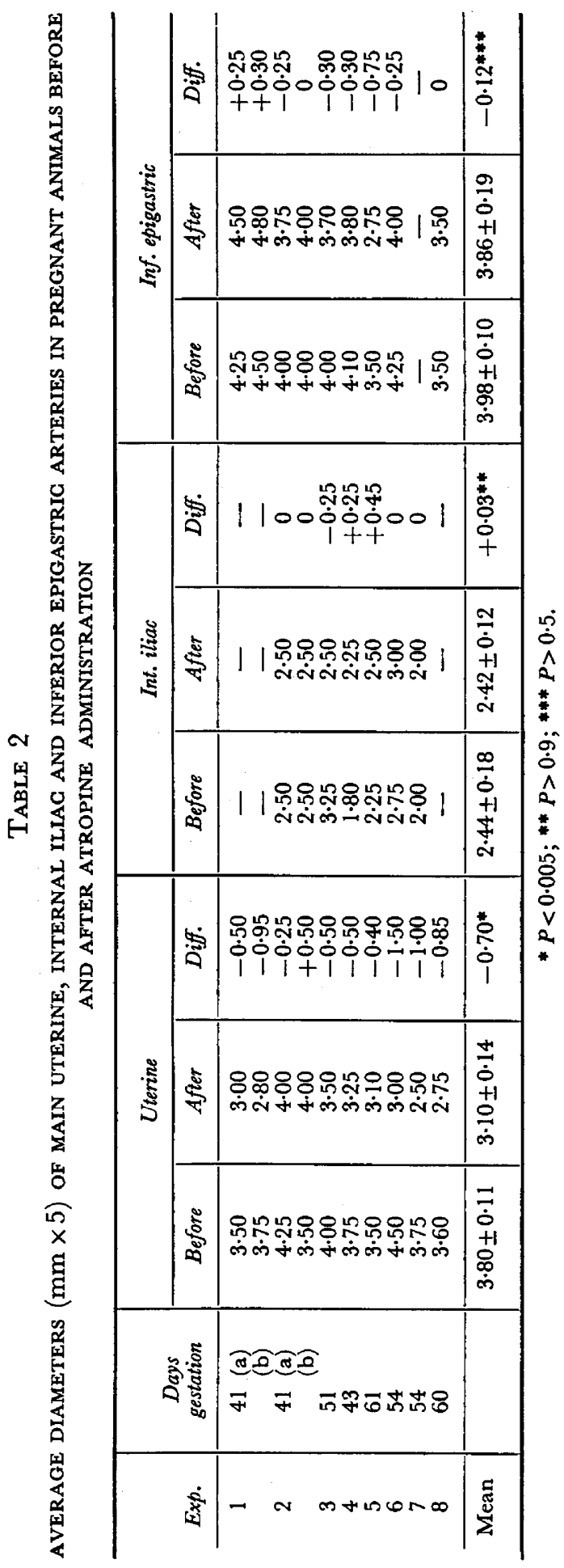


Plate I
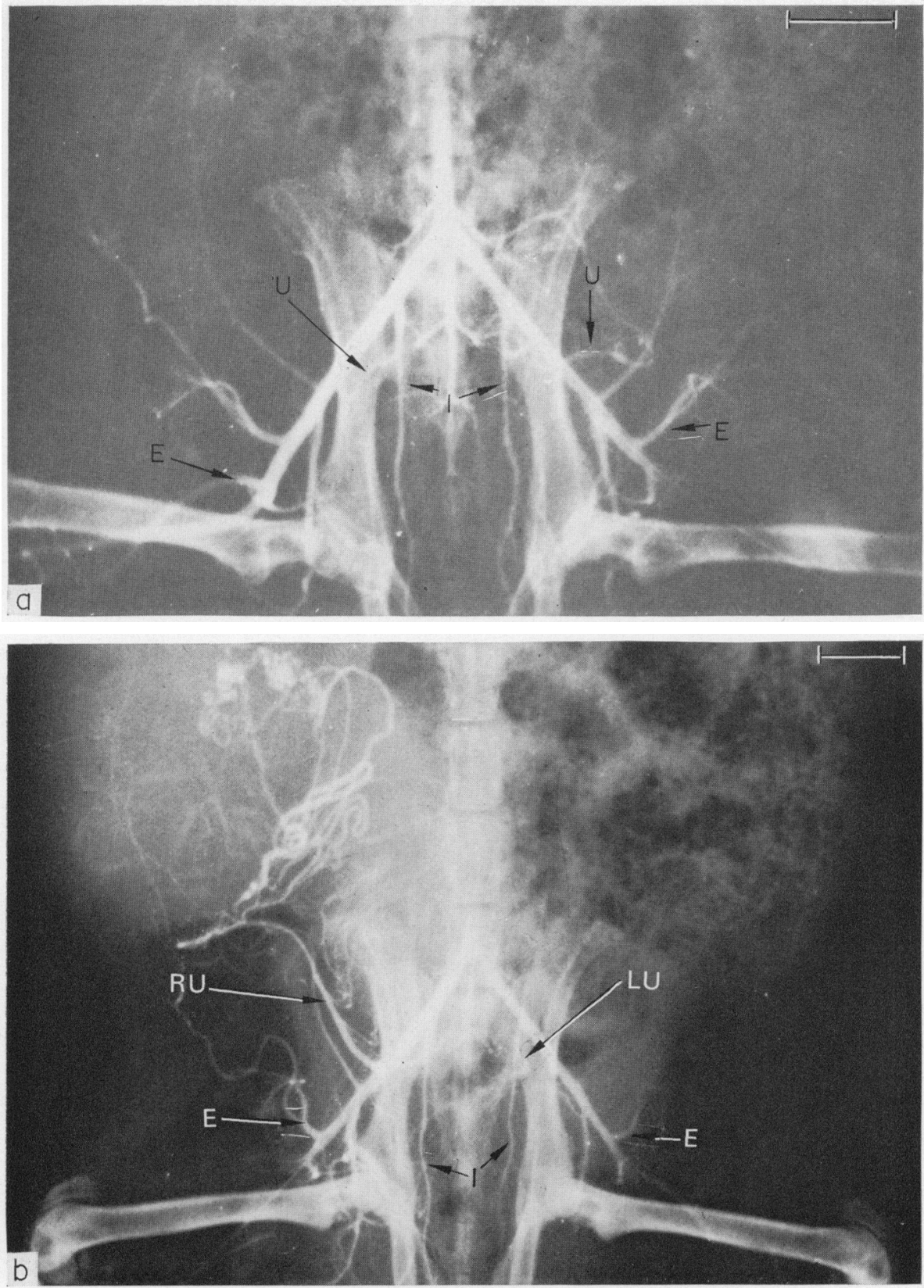

Fis, 1. Arteriographs of the pelvie vessels in wo female guinea-pigs. a lirgin, showing main utcrine arteries ( $L$ internal iliac arteries $I$ and inferior cpigastric anteries $\mathrm{E}$ ? (b) Pregnand 60) days. Foetus in right hom only. Note the enlargenent of the uterine artery on this side $(\mathrm{RL})$ and the absence of enlargenent of the contralateral artery (L, L j. The calibrations represent centimetres on the original contact $X$-ray plate. 

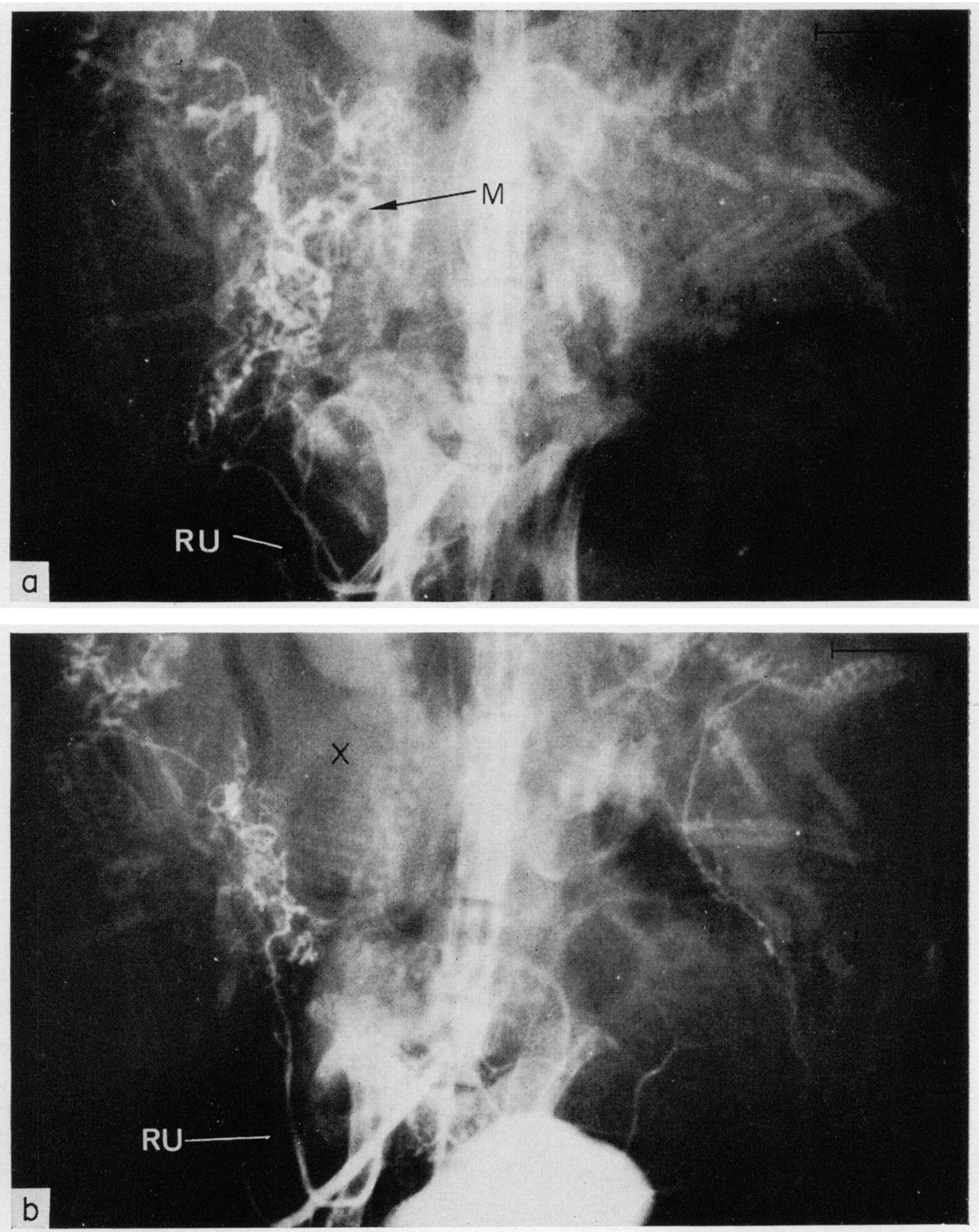

Fiti, 2. Arteriographs of the pelvic vessels in a pregnant guinea-pig (Fxp. 6. ia Control. Vote the right utcrine artery ( $\mathrm{R} \mathrm{C}$ ) giving rise to numerous mesometrical ressels ( $\mathrm{M}$. b) 15 min after administration of atropine $0 \cdot 5 \mathrm{mg} / \mathrm{kg}$. Note the disappearance of some of the spiral mesometriat arterics after atropine $X$. A segmental constriction of the common iliac artery atter atropine is visible. The calibrations represent centimetres on the original X-ray plate. 
Examination of animals of 40 or more days' gestation revealed that massive dilatation of the uterine arteries supplying the pregnant uterine horns had occurred. In cases of unilateral pregnancy, this dilatation was restricted to the pregnant side, the other uterine artery remaining similar in diameter to those observed in the virgin population (Pl. l, cf. Figs. 1 a and b). The mean diameter of uterine arteries supplying pregnant horns in the eight animals examined was $3.80 \mathrm{~mm}$ (actual value $0.76 \mathrm{~mm}$ ) which represented an increase of $67 \%$ over the mean diameter in the virgin animals (Table 2). It was of interest to note that there did not seem to be any further consistent increase in uterine arterial diameter after 40 days' gestation (Table 2).

In the pregnant animals, atropine administration resulted in a mean decrease in diameter of the uterine arteries of $0.70 \mathrm{~mm}$ (actual value $0.14 \mathrm{~mm}$ ) or $40 \%$ of the enlargement due to pregnancy (Table 2). On statistical analysis, the reduction in diameter following atropine was found to be statistically significant at the $P=0.005$ level. In contrast to the effect on uterine arterial diameter, atropine produced no significant alteration in the diameter of the other arteries measured (Table 2). The effect of atropine was as pronounced in a dose of $0.1 \mathrm{mg} / \mathrm{kg}$ as it was at higher doses.

In three experiments, atropine administration was associated with apparent closure of some of the spiral arteries in the uterine wall (Pl. 2, cf. Figs. $2 \mathrm{a}$ and b). In the other experiments, this effect was not discernible.

\section{DISCUSSION}

Possible quantitative errors may have affected the results of this study, both through variation in the experimental situation-depth of anaesthesia, cumulative toxicity of medium, stage of cardiac cycle or stage of pregnancy-and through the limitation of accuracy of measurements imposed by the coarse grain and double emulsion of the high speed X-ray plates needed. Attempts were made to compensate for these sources of error by taking multiple photographs during each experimental sequence, by using other arteries in the pelvic region as controls for the uterine artery and by having measurements made by two observers, each working independently and without knowing the identity of the photographs.

In animals in the last half of pregnancy, the diameter of the uterine artery supplying a pregnant uterine horn was increased by a mean value of $67 \%$. By contrast, the other arteries studied showed no change of diameter in pregnancy. These results agree with those of Smith, Walters \& Spong (1968) who found, using arteriography in the rabbit, that the uterine arterial diameter increased during pregnancy by $24 \%$ but that the diameter of nearby nonuterine vessels was unchanged.

The possible mechanisms underlying uterine arterial enlargement during pregnancy were listed by Smith et al. (1968). There might be a direct haemodynamic effect due to changes in pressure gradients, as indicated for the production of collateral circulation by John \& Warren (1961). Alternatively, there might be a dilator influence, either by circulating or local hormones or by the action of vasodilator nerves. In the present study, arterial enlargement was 
found to be restricted to the artery supplying the pregnant uterine horn, and a similar situation was noted by Smith et al. (1968) in the rabbit. This suggests that the enlargement is unlikely to be primarily due to a circulating hormonal influence in either species. In the guinea-pig, the enlargement is also unlikely to be due to a haemodynamic mechanism since atropine caused a selective reduction in the diameter of those uterine arteries enlarged by pregnancy. This suggests the existence during pregnancy of an active vasodilatation due to the action of an acetylcholine-like substance. However, in view of the facts that atropine produced only partial restoration to the pre-pregnant arterial diameter, and that there is considerable hypertrophy of the vessel wall during pregnancy (Albert \& Bhussry, 1967; Bell, 1969a), there may be some additional structural contribution to the luminal enlargement. This could be haemodynamic in origin.

The cholinergic vasodilatation could be explained on the basis of a local hormonal influence by an acetylcholine-like substance (Reynolds, 1949; Burn, 1954; Greiss \& Marston, 1965). However, the presence of cholinergic vasodilator nerve fibres in the guinea-pig uterine artery has been demonstrated using both pharmacological and histochemical techniques and it has further been shown that these nerves are functional only during the latter half of pregnancy (Bell, 1968, 1969a). Thus, it is probable that the atropine-sensitive dilatation observed is neurogenic in nature.

Although the precise time for the appearance of responsiveness of the vessel to cholinergic stimuli during pregnancy has not yet been systematically studied, it appears to be not before the 4th week of gestation and may vary considerably between individual animals (C. Bell, unpublished observations). The relatively weak effect of atropine in Exp. 2 of the present study might therefore conceivably be due to the fact that in this particular animal, the cholinergic nerves were not yet functional.

It must be emphasized that these results cannot be extrapolated to all other species. Histochemical studies have revealed that although similar cholinergic nerves appear to exist in the uterine arteries of man, dog and pig, they are absent in a number of other species, including the rabbit (Bell, 1969b, 1971). In these cases, therefore, other factors must be responsible for the production of uterine hyperaemia of pregnancy.

\section{ACKNOWLEDGMENTS}

G.B. would like to thank Dr M. Vogt for her hospitality and interest in this work, and the National Heart Foundation of Australia for financial support as an Overseas Research Fellow. We are also grateful to Mr A. L. Gallup, Chief Photographer of the Institute, for his co-operation, Dr C. O. Hebb for her comments on the manuscript and Miss C. Smy for technical assistance.

\section{REFERENGES}

Albert, E. N. \& Bhussry, B. R. (1967) Effects of multiple pregnancies and age on the elastic tissue of uterine arteries in the guinea-pig. Am. F. Anat. 121, 259.

Assaly, N. S., Rauramo, L. \& Peltonen, T. (1960) Measurement of uterine blood flow and uterine 
metabolism. VIII. Uterine and fetal blood flow and oxygen consumption in early human pregnancy. Am. F. Obstet. Gynec. 79, 86.

Barcroft, J. \& Barron, D. H. (1946) Observations upon the form and relations of the maternal and fetal vessels in the placenta of the sheep. Anat. Rec. 94, 569.

BELL, G. (1968) Dual vasoconstrictor and vasodilator innervation of the uterine arterial supply in the guinea-pig. Circulat. Res. 23, 279.

BeLl, C. (1969a) Fine structural localization of actylcholine-esterase at a cholinergic vasodilator nervesmooth muscle synapse. Circulat. Res. 24, 61.

BELL, C. (1969b) Evidence for dual innervation of the human extrinsic uterine arteries. 7. Obstet. Gynaec. Br. Commonw. 76, 1123.

BELL, G. (1971) Distribution of cholinergic vasomotor nerves to the parametrial arteries of some laboratory and domestic animals. F. Reprod. Fert. 26, 53.

Burn, J. H. (1954) Acetylcholine as a local hormone for ciliary movement and the heart. Pharmac. Rev. 6, 107.

DRAPER, R. L. (1920) The pre-natal growth of the guinea-pig. Anat. Rec. 18, 369.

FisHer, R. A. (1936) Statistical methods for research workers. Oliver \& Boyd, Edinburgh.

Greiss, F. G., Jr \& Anderson, S. G. (1970) Uterine blood flow during early ovine pregnancy. Am. $\mathcal{F}$. Obstet. Gynec. 106, 30.

Greiss, F. C., JR \& Marston, E. L. (1965) The uterine vascular bed: effects of estrogens during early ovine pregnancy. Am. F. Obstet. Gynec. 95, 720.

John, H. T. \& WARren, R. (1961) The stimulus to collateral circulation. Surgery, St. Louis, 49, 14.

Metcalfe, J., Romney, S. L., Ramsey, L. H., Reid, D. E. \& Burwell, G. S. (1955) Estimation of uterine blood flow in normal human pregnancy at term. F. clin. Invest. 34, 1632.

Orsin, M. W. (1957) The vascular knot of the hamster uterus: the placental arterial supply and its changes during gestation and post-partum involution. 7. Morph. 100, 565.

Ramsey, E. M. (1959) Vascular adaptations of the uterus to pregnancy. Ann. N.Y. Acad. Sci. 75, 726.

Reynolds, S. R. M. (1949) Physiology of the uterus, 2nd edn. Hoeber, New York.

Smtth, J. C., Walters, W. A. W. \& Spong, J. E. (1968) Effects of pregnancy on the diameter of the uterine arteries in the rabbit. Pelvic arteriography. Obstet. Gynec., $\mathcal{N} . Y .31,788$. 